\title{
A Teologia da Enearnação em Irineu de Lion como superação da heresia gnóstiea
}

Recebido: 09/05/2016. Aprovado: 16/05/2016.

\author{
Vitor Galdino Feller* \\ Edegar Fronza Júnior**
}

Resumo: O artigo tem como objetivo principal apresentar a teologia de Irineu como resposta a heresia gnóstica do século II. A pesquisa tem seu eixo central no desenvolvimento do conceito de encarnação como elemento central da fé cristã e da dinâmica imprescindível da autocomunicação de Deus para a humanidade. Em Adversus Haereses, Irineu desenvolverá uma teologia da encarnação na qual o homem é criado para que viva e manifeste a glória divina. A ênfase não se encontra na queda original, o lapso dos primeiros pais, mas no plano de amor e salvação de Deus para o ser humano. Jesus é o rosto visível do Pai que veio unir e reunir em si todas as coisas. Através da encarnação-redenção, o Filho entra na história e restitui a bondade e pureza originárias perdidas por Adão e Eva no paraíso.

Palavras-chave: Irineu. Encarnação. Gnosticismo. Autocomunicação.

Abstract: The article aims presenting Ireneu's theology as an answer to the Gnostic heresy by the end of the 2nd century. The research has its central axis in the development of the concept of incarnation as the central element of the Christian faith and of the indispensable dynamics of God's auto-communication with humankind. In Adversus Haereses, Ireneus will develop a theology of the incarnation in which man is created in order to live and to manifest divine glory. Emphasis is not found in the original fall, the lapse of our first parents, but in the project of love and salvation of God in favor of the human being. Jesus is the visible face of the Father who went to unite and reunite in him all things. Through the incarnation-redemption, the Son enters in the history and restores the original bounty and purity which were lost by Adam and Eve in the paradise.

Key-words: Ireneus. Incarnation. Gnosticism. Auto-communication.

* Doutor em Teologia pela Pontifícia Universidade Gregoriana, de Roma (1987). Professor de Teologia Sistemática na Faculdade Católica de Santa Catarina. Vigário Geral da Arquidiocese de Florianópolis.

** Bacharel em Filosofia pela Faculdade São Luiz, de Brusque (2011). Licenciatura em Filosofia pela Universidade Federal de Santa Catarina, de Florianópolis (2015). Bacharel em Teologia pela Faculdade Católica de Santa Catarina (2015). Mestrando em Filosofia pela Universidade Federal de Santa Catarina na área de Ética e Filosofia Política. 
A partir de meados do século II, acontece uma nova configuração na literatura cristã. A Patrística que se caracterizava por um corpus com ênfase na pastoral e na liturgia, desloca seu eixo de reflexão para uma literatura de caráter cientifico ${ }^{1} \mathrm{em}$ forma de apologética. Enquanto no primeiro século da Igreja primitiva a preocupação estava relacionada a questões ad intra, ou seja, manter a boa ordem e a unidade nas comunidades, exortá-las ao martírio e à busca de conversão, o segundo século assenta sua reflexão na defesa teórica da fé e na ilustração desta, especialmente voltada aos adversários externos, judeus e pagãos e posteriormente, àqueles adversários presentes no interior das comunidades, os hereges.

\section{O gnosticismo e a reação de Irineu}

O movimento gnóstico provocou uma verdadeira revolução espiritual e teológica, na segunda metade do século II, sendo reservado às elites da sociedade. Recorda as religiões mistéricas presentes no Oriente Médio, especialmente Egito, Pérsia e Grécia. Com características salvíficas e universais, buscava imprimir o caráter mágico nas cerimônias, agregando a si as forças da natureza. $\mathrm{O}$ culto mistérico atualizava um evento, geralmente paixão, morte e retorno à vida de algum personagem importante.

O gnosticismo do século II "designa uma tendência constante do espírito humano que busca o sentido da vida no conhecimento. [...] É um vasto movimento religioso cujo desenvolvimento é contemporâneo das origens do cristianismo". ${ }^{2}$ A salvação, para o gnosticismo, dá-se por meio do conhecimento que é essencialmente o conhecer-se ou reconhecer o elemento divino que constitui o verdadeiro "eu". Deste modo, ao lado do dualismo antropológico, o gnosticismo nega a soteriologia e a teologia da revelação, pois relativiza a salvação por meio de Jesus ao passo que afirma a salvação individual sem ajuda da graça divina.

1 O caráter de cientificidade se expressa pela sistematização, organização em forma de defesa registrada pela literatura dessa época. Há uma preocupação tanto com o conteúdo quanto com a forma como este será apresentado. Não se refere à ciência no sentido moderno do termo.

2 SESBOÜÉ, B.; WOLINSKI, J. O Deus da salvação: a tradição, a regra de fé e os símbolos, a economia da salvação, o desenvolvimento dos dogmas trinitário e cristológico. São Paulo: Loyola, 2002. v. 1. p. 38. 
Alguns dos principais argumentos combatidos pelos Santos Padres em relação ao gnosticismo ${ }^{3}$ são: 1 . A distinção entre o Deus desconhecido e transcendente, revelado por Jesus, e o Deus demiurgo; 2 . O ser humano é um raio da luz divina aprisionado num corpo material que submetido pelo demiurgo a este mundo só pode proceder de uma divindade inferior; 3 . O verdadeiro meio de salvação é a gnose, caminho secreto pelo qual o ser humano toma consciência de sua verdadeira natureza e origem celestial. ${ }^{4}$

Dentro desse contexto de forte influência do gnosticismo frente ao cristianismo e da proliferação das heresias, surge o nome de Irineu de Lion. O contexto da vida de Irineu foi um importante fator para o desenvolvimento de seus escritos e sua apologética. Sua amizade com Policarpo, que por sua vez foi discípulo do próprio João evangelista, será de grande valia para que possua um "senso cristão sólido, que faz com que seu pensamento seja, no conjunto, mais seguro que o dos Apologistas contemporâneos, e um notável equilíbrio em face da proliferação de doutrinas aberrantes na Ásia Menor". ${ }^{5}$

O corpus irineano, fortemente marcado pela doutrina do Verbo, enfatizado no prólogo joanino, juntamente com as epístolas paulinas, será responsável pela transmissão ativa da fé, o que com o tempo se constituirá como Depositum Fidei. Seu legado se baseia principalmente na afirmação da Tradição Apostólica, tal e qual como recebida dos apóstolos. Ele foi o guardião fiel dos "cânones imutáveis".

Irineu foi, antes de tudo, um grande pastor. E suas preocupações pastorais levaram-no a escrever as obras que se conservam até nossos dias. A mais importante se chama Adversus Haereses, título comumente traduzido por Refutação da falsa gnose. Nesta obra Irineu desenvolverá uma "suma" anti-gnóstica que influenciará posteriormente teólogos como Tertuliano, Hipólito de Roma e Atanásio.

3 O presente resumo, no intuito de delimitar a pesquisa, quando trata do gnosticismo, refere-se a essa corrente filosófica do século II, já que tal movimento se apresenta abrangente na história da Igreja, bem como na filosofia.

4 ETCHEVERRÍA, C. Patrologia. Madrid: BAC, 1994, p. 49.

5 LIÉBAERT, J. Os padres da Igreja, séculos I ao IV. 2. ed. Tradução: Nadyr de Salles Penteado. São Paulo: Loyola, v. 1, 2000, p. 53. 


\section{A antropologia e a soteriologia de Irineu}

O centro da teologia irineana, na Adversus Haereses, obra central no desenvolvimento de sua teologia da encarnação, será fundamentada na proposta paulina da relação entre Criador e criatura. Deste modo, "cria um antropocentrismo cuja força é o teocentrismo, sem nenhum dualismo". 6

O homem é um ser criado para Deus, não um espírito decaído, um fragmento celeste, alguém totalmente corrompido sem capacidade de chegar até a divindade, mas um corpo "pneumatizado".

Deus faz, o homem é feito. [...] Deus faz o bem, o homem recebe o bem. Deus é perfeito em tudo, igual e idêntico a si mesmo, é por inteiro luz, pensamento, substância e fonte de todos os bens, enquanto o homem recebe o progredir e o crescer para Deus. Enquanto Deus é o mesmo, o homem que se encontra em Deus progredirá sempre em direção a Deus. Deus não cessa de beneficiar e enriquecer o homem e o homem de ser beneficiado e enriquecido por Deus. ${ }^{7}$

O homem é um ser criado para que viva e veja a manifestação da glória divina. "Porque a glória de Deus é o homem vivo e a vida do homem é a visão de Deus". ${ }^{8}$ Ao mesmo tempo, Irineu entende o ser humano formado por três dimensões: corpo, alma e espírito. Estas, por sua vez, participam da restauração e da ressurreição em Cristo, assim como na teologia paulina "pois tudo o que sois, espírito, alma e corpo, seja conservado sem mancha alguma para a vinda de Nosso Senhor Jesus Cristo (1Ts 5,23). A salvação, em outras palavras, devolve ao ser humano sua bondade e perfeição originárias, já que estas não foram totalmente perdidas pelo pecado de Adão e Eva.

O homem perfeito é a mistura da união da alma que recebeu o Espírito do Pai e que foi misturada à carne modelada segundo a imagem de Deus. [...] As três coisas devem ser restauradas e reunidas, e não há para elas senão uma única salvação [...] Porque os espíritos sem corpos jamais serão homens espirituais; mas é nossa substância isso

\footnotetext{
6 RIBEIRO, 1995, p. 19.

7 IRINEU DE LIÃO, 1995, p. 394-395 (Ad. Haer. IV, 2, 11,2-11,3).

8 IRINEU DE LIÃO, 1995, p. 433-434 (Ad. Haer. IV, 3, 20,8-20,9).
} 
é, o composto de alma e carne que, recebendo o espírito de Deus, constitui o homem espiritual. ${ }^{9}$

O humano é um ser em desenvolvimento. Esse processo acontece no ritmo diário dando a possibilidade do amadurecimento gradual humano em busca da perfeição. O ser humano não é perfeito nem imperfeito, antes é capaz de aperfeiçoar-se à medida que vai crescendo em direção a Deus. ${ }^{10}$ Neste caminho, há um processo do homem de acostumar-se a Deus, progredindo no seu conhecimento. Assumindo a carne, o Verbo livra o ser humano da morte e do pecado e o restitui à visão divina.

Se alguém perguntasse: Ora! Deus não podia fazer o homem perfeito desde o princípio? Saiba que no que diz respeito a Deus, que é incriado e sempre igual a si mesmo, tudo era possível, mas as suas criaturas, enquanto receberam depois o início da existência, eram necessariamente inferiores a quem as fez. [...] Esta é a ordem, o ritmo, o movimento pelo qual o homem criado e modelado adquire a imagem e semelhança do Deus incriado: o Pai decide, o Filho executa e forma, o Espírito nutre e aumenta, o homem paulatinamente progride e se eleva à perfeição, isto é, se aproxima do Incriado, perfeito por não ser criado, e este é Deus. ${ }^{11}$

O ser humano é livre e responsável. Assim como Deus, o homem é dotado de liberdade, responsabilidade e todos os seus atos possuem um caráter de escolha, tanto para o bem como para o mal. Os atos humanos só o realizaram plenamente quando em comunhão com o plano de salvação divino. $\mathrm{O}$ homem pecou, usou sua liberdade buscando a si mesmo, deixando-se enganar, como uma criança pelo Sedutor. Contudo Deus, em Jesus Cristo, reabre as portas da salvação para toda a humanidade.

O plano de Deus para o ser humano é sua plena realização através da salvação. Esse plano se realiza na história do ser humano, culminado na encarnação/redenção. O homem e a mulher são chamados a optar pelo bem. Podem, contudo, opor-se à vontade divina como no primeiro Adão, perdendo não definitivamente sua pureza e bondade originárias. Cristo, o "Novo Adão", assumindo o ser humano na carne, resgata o homem da maldade e o recupera levando-o ao caminho da salvação. "O Verbo encarnado revelou e visibilizou o Pai ao homem e por meio de seu Espírito a humanidade o encontrou outra vez. É ele o único capaz de reunir todas

$9 \quad$ IRINEU DE LIÃO, 1995, p. 47; 52-54 (Ad. Haer. I, 6, 1,8,1-8,3).

10 IRINEU DE LIÃO, 1995, p. 394-395 (Ad. Haer. IV, 2, 11, 2).

11 IRINEU DE LIÃO, 1995, p. 504-508 (Ad. Haer. IV, 4, 38,1-38,4). 
as coisas, isto é: de recapitular tudo". ${ }^{12}$ Ao fazer-se "adamítico" Cristo renova não só o homem, restituindo-lhe graça e dignidade originárias, mas também toda a criação. A encarnação é fator imprescindível para que a obra da salvação possa ser cumprida.

Que trouxe de novidade a vinda do Senhor? Ficai sabendo que trouxe toda a novidade, trazendo a si mesmo, que fora anunciado. Com efeito, o que foi predito é que a novidade viria para renovar e vivificar o homem. ${ }^{13}$

\section{A retomada de Irineu no Magistério pós-conciliar}

Nos tempos hodiernos, especialmente com o Vaticano II, a Patrística começou a retomar seu lugar de destaque na teologia. Com a proposta dos padres conciliares de "voltar às fontes", a Igreja foi chamada a alargar os horizontes, não enrijecendo ou engessando a verdade evangélica a períodos da Tradição.

A "volta às fontes" não significa reproduzir tal e qual a mensagem das comunidades primitivas para nossa realidade como uma matriz pronta na qual se deve encaixar toda a reflexão teológica. Isso seria um contra senso. Antes, a partir dos dados das primeiras comunidades, buscar lançar luzes e pistas de ação prática para o mundo contemporâneo sem perder de vista o conteúdo originário doutrinal e de fé de nossos Pais e Mães da Igreja.

A obra de Santo Irineu, caracterizada por sua universalidade e genialidade, destaca-se entre a história dos pensadores cristãos. Isso porque oferece não só uma síntese da história da salvação, em fidelidade à Tradição apostólica; mas também a proposta de uma teologiaantropologia otimista em que o plano de amor e salvação encarnado no projeto de Jesus humano-divino é maior que a força do pecado. Neste sentido, encontramos nos documentos da Igreja, desde Lumen Gentium até Gaudium et Spes e, por conseguinte, na realidade latino-americana de Medellín a Aparecida, uma teologia que parte da encarnação como fato fundante para a construção do ser e agir da Igreja, mais comprometida com a sociedade e o mundo contemporâneo.

12 HAMMAN, 1995, p. 22.

13 IRINEU DE LIÃO, 1995, p. 481-482 (Ad. Haer. IV,34,1). 
A concepção do "ser humano total" perpassa todos os documentos do Concílio. Em Dignitatis Humanae, logo no primeiro capítulo os padres conciliares afirmam: "O próprio Deus manifestou ao gênero humano o caminho pelo qual os homens, servindo a ele, pudessem salvar-se e tornar-se felizes em Cristo". ${ }^{14} \mathrm{O}$ ser humano é capax Dei" (capaz de Deus), chamado a reconhecer a centralidade de Cristo como origem, fundamento e télos ${ }^{15}$ da sua existência.

Tanto Lumen Gentium como Gaudium et Spes recuperam a perspectiva da centralidade do plano salvífico de Deus e de seu amor pela humanidade. Cristo nos quer fazer partícipes de sua vida, tornando-nos à sua imagem e semelhança como no início da criação.

O Pai eterno por libérrimo e arcano desígnio de sua sabedoria e bondade criou todo o universo. Decretou elevar os homens à participação da vida divina. E caídos em Adão, não os abandonou, oferecendo-lhes sempre os auxílios para a salvação em vista de Cristo. ${ }^{16}$

Enquanto peregrinos neste mundo, somos chamados em última instância a promover um mundo mais humano, que terá sua concretização última na glória de Deus. O amor a Deus e a vivência do mandamento novo são os modos pelos quais o ser humano vai se santificando e transformando o mundo e a sociedade. "Semelhantemente, a Igreja cerca de amor todas as pessoas afligidas pela fraqueza humana, e reconhece especialmente nos pobres e sofredores a imagem de seu Fundador pobre e sofredor; e neles procura servir Cristo". ${ }^{17}$

Na mesma linha de Lumen Gentium e Gaudium et Spes, se desenvolve na América Latina uma teologia que se interessa pelo ser humano e sua realidade. Logo no início o Documento de Medellín alerta que "para conhecer a Deus é necessário conhecer o homem, pois Cristo é aquele em quem se manifesta o mistério do homem". ${ }^{18}$ Essa introdução deixa claro que o interesse do episcopado latino-americano e caribenho é entender o homem à luz de Cristo, porém inserido numa realidade diversa do mundo europeu.

\footnotetext{
14 CONCÍLIO VATICANO II, 1997, p. 411-413 (DH 1).

15 Finalidade, fim para o qual se destina algo.

16 CONCÍLIO VATICANO II, 1997, p. 102-103 (LG 2a).

17 CONCÍLIO VATICANO II, 1997, p. 547-548 (GS 8b).

18 CELAM, 2007, p. 73 (DM 1).
} 
O Documento de Puebla segue o mesmo ritmo de Medellín. No entanto parece apresentar duas antropologias, duas cristologias e duas eclesiologias, uma de caráter mais dogmático-doutrinal com o intuito de preservar os conteúdos da fé e outra de caráter histórico-cultural-pastoral. É importante salientar que apesar deste contraste existente neste documento, há uma preocupação em inserir a reflexão teológico-dogmática no chão do continente. ${ }^{19}$

A antropologia de Puebla não consegue conjugar a visão de um homem refém da ordem econômica e social; antes, busca apresentar a dimensão profética. O Documento de Aparecida avança sobre isso, com propostas mais candentes a respeito do ser humano situado na história. "As visões e práticas do determinismo, do psicologismo, do economicismo, do consumismo, do liberalismo capital, do tecnicismo e do cientificismo acabam por desfigurar a imagem de Deus". ${ }^{20} \mathrm{E}$ acrescenta: "Já não se trata simplesmente do fenômeno da exploração ou opressão, mas de algo novo: a exclusão social. [...] Os excluídos não são somente 'explorados', mas 'supérfluos' e 'descartáveis'". ${ }^{21}$ $\mathrm{O}$ encontro com Jesus é uma experiência viva que nos desinstala, e nos convoca a anunciar a boa nova de libertação a todos os povos. Em Jesus Cristo, Verbo Criador (Jo 1,3) e encarnado (Jo 1,14), temos a perfeita revelação do homem ao próprio homem e a expressão da sublimidade de sua vocação. ${ }^{22}$

Em profunda consonância com Irineu e o Concílio Vaticano II, as conferências episcopais latino-americanas apontam para Cristo como o ideal do homem novo. Na verdade ele é o "protótipo" da realização humana. A vida oculta de Jesus em Nazaré é a escola do Evangelho. Ali ele aprende a lição familiar, do trabalho, da fé, da sociedade como "Filho do carpinteiro". Jesus aprende a humildade, a obediência. Compartilha as condições da vida pobre de sua família, suas limitações, alegrias e dificuldades.

\footnotetext{
19 FELLER, V.G. A antropologia cristã no magistério episcopal Latino-Americano. Encontros Teológicos, Florianópolis: ITESC, v. 21, n. 45, p. 57-65.

20 CELAM, 2007, p. 140-144 (DAp 305-315).

21 CELAM, 2007, p. 39-40 (DAp 65).

22 CELAM, 1992, p. 599-600; 706-707 (SD 13;159).
} 


\section{Conclusão}

A teologia de Irineu é um convite a um olhar contemplativo sobre a temática da encarnação do Verbo como um fato crucial para o entendimento de toda a história da salvação. Por muito tempo criaram-se imagens triunfalistas de Deus, baseadas em termos filosóficos e teológicos que não tocavam o chão existencial das pessoas. O Jesus professado na fé eclesial, por vezes, parece traduzir mais um ideal de perfeição, algo distante, ao invés de nos aproximar de Deus. Deste modo, esse Jesus é vivido numa fé intimista, individualista, pietista ou meramente sacrificial.

O Jesus da teologia irineana possui um corpo, um rosto, uma personalidade humana. Isso porque, encarnado na história Ele traz consigo tudo aquilo que é realmente identitário da humanidade. Sendo assim, percebe-se que a proposta de Irineu vem ao encontro da teologia contemporânea, pois convida a uma reflexão aprofundada acerca de Jesus, sua natureza, sua história e seu projeto para humanidade.

\section{Referências}

CONSELHO EPISCOPAL LATINO AMERICANO. Documento de Aparecida: texto conclusivo da V Conferêrencia Geral do Episcopado Latino-Americano e do Caribe. São Paulo: Paulus, 2007.

. Puebla grandes temas. São Paulo: Paulinas, 1978.

. Documento de Santo Domingo: nova evangelização, promoção humana e cultura cristã. São Paulo: Paulinas, 1992.

. A Igreja na atual transformação da América Latina à luz do Concílio: conclusões de Medellín. Petrópolis: Vozes, 1969.

CONCÍLIO VATICANO II. Declaração Dignitatis Humanae sobre a liberdade religiosa. In: COSTA, Lourenço (Org.). Documentos do Concílio Ecumênico Vaticano II. São Paulo: Paulus, 1997. v. 1.

. Constituição pastoral Gaudium et Spes sobre a Igreja no mundo de hoje. In: COSTA, Lourenço (Org.). Documentos do Concílio Ecumênico Vaticano II. São Paulo: Paulus, 1997. v. 1.

. Constituição dogmática Lumen Gentium sobre a Igreja. In: COSTA, Lourenço (Org.). Documentos do Concílio Ecumênico Vaticano II. São Paulo: Paulus, 1997. v. 1. 
ETCHEVERRÍA, Ramón T. Patrologia. Madrid: BAC, 1994.

FELLER, Vitor Galdino. A antropologia cristã no magistério episcopal latino-americano. Encontros Teológicos, Florianópolis: Itesc, v. 21, n. 45, p. 57-65, 2006.

HAMMAN, G. A. Para ler os Padres da Igreja. Tradução: Bênoni Lemos. São Paulo: Paulus, 1995.

IRINEU DE LIÃO. Livros I, II, III, IV, V. Tradução: Lourenço Costa. São Paulo: Paulinas, 1995.

LIÉBAERT, Jacques. Os padres da Igreja - séculos I ao IV. 2. ed. Tradução: Nadyr de Salles Penteado. São Paulo: Loyola, 2000. v. 1.

RIBEIRO, Hélcion. In: IRINEU DE LIÃO. Livros I, II, III, IV, V. Tradução: Lourenço Costa. São Paulo: Paulinas, 1995.

SESBOÜÉ, Bernard; WOLINSKI, Joseph. O Deus da salvação: a tradição, a regra de fé e os símbolos, a economia da salvação, o desenvolvimento dos dogmas trinitário e cristológico. São Paulo: Loyola, 2002. v. 1.

E-mail dos autores: vitorfeller@arquifln.org.br edegarfronza@gmail.com 